\title{
The Development of Nano-technology and Its Industrialization in DPR of Korea
}

\author{
Un-Gyong Ri, Hyok-Chol Kim* \\ Faculty of Economics, Kim Il Sung University, Pyongyang, DPR of Korea
}

Email address:

ryongnam4@yahoo.com (Hyok-Chol K.)

${ }^{*}$ Corresponding author

\section{To cite this article:}

Un-Gyong Ri, Hyok-Chol Kim. The Development of Nano-technology and Its Industrialization in DPR of Korea. Journal of World Economic Research. Vol. 6, No. 1, 2017, pp. 1-4. doi: 10.11648/j.jwer.20170601.11

Received: October 18, 2016; Accepted: December 3, 2016; Published: February 24, 2017

\begin{abstract}
The essay describes international trend of Nano-tech industrialization, the achievements the DPRK made in the field of Nano-technology, the development of Nano-technology at present time and problems raised in its industrialization. Nanotechnology, along with IT and bioengineering, emerged as core, basic technology in the early twenty-first century and can now bring about a radical turn in developing all fields of science and technology and contribute greatly to developing economy and building up national defence. Therefore, great attention is paid in many countries to developing and introducing it into industry. In line with the trend of developing nanotechnology, the DPR of Korea worked out the national strategy of developing it and on this basis, is now conducting a dynamic campaign to develop and introduce it into industry.
\end{abstract}

Keywords: Nano-technology, Nano-tech Industrialization, Nano-material, Nano-tech Application

\section{International Trend of Nano-tech Industrialization}

Today, in many countries around the world, Nanotechnology is put up as a matter of vital importance closely related to the rise and fall of the nation and its development is given a great significance. This can be explained in relation with the unique nature of Nano-technology.

Nano-technology is an advanced technology that produces a new substance by manipulating and arranging their atoms and molecules based on the study of the structure and nature of hyperfine matters of nano-size $(0.1 \sim 100 \mathrm{~nm})$. Considering the fact that atoms and molecules are usually nano-sized, Nano-technology can be defined as a technology that produces and uses targeted substances by direct manipulation and arrangement of atoms and molecules.

When a particle of a substance is nano-sized or its material has nano-class structure, there appears some unique physical and chemical properties which could not be seen in the original substance. Nano-technology fabricates and uses substances so that such properties appear. Therefore, today, with the help of Nano-technology, the problems that could not be realized with former technologies and the mysterious problems that have remained only as estimates and ideals are turning into reality.

The world put forward Nano-technology as a new "Industrial Revolution" and this clearly shows how significant Nano-technology is. This means that just as capitalism achieved a rapid development from industrial revolution in the last century, the introduction of Nanotechnology today will bring about a fresh leap in all sectors of social life, such as economy, national defense and etc.

Nano-technology has already been introduced to practice and is yielding a number of economic advantages.

For this reason, many countries are making every possible effort in order to have a global competitiveness in this sector by rapidly developing Nano-technology and accelerating its industrialization.

First of all, they are increasing the investment on this sector.

Nano-technology requires advanced technologies and equipment as its foundation and its industrialization process calls for a lot of fund invested and a long and stable support.

Generally, the process of industrialization is divided into 7 big stages/phases: provisional test, middle test, industrial production, opening-up of a market, profit earning, production stability and declining. Developing a new 
technology or a new product starts from a small-scale laboratory research and industrialization must go through an extensive phase of middle test. If and when the research results of middle test are proved to be successful, it will go over to the next stage, i.e. massive production. And when the developed product becomes popular on the market, the production will take place in a more active way.

In case of Nano-tech industrialization, the first four stages demand for a large amount investment. The ratio of investment on provisional test, middle test and industrial production is 1:10:100 and the phase of opening up a new market call for even larger sum of fund.

Taking this into consideration, many countries are investing vast amount of fund in Nano-tech sector. Internationally, the investment on Nano-tech sector records tens of billions of US\$ annually and, in 2015, the distribution cost related to Nano-technology reached 2 trillion and several hundred billion US\$.

Secondly, they are establishing an inspection system in relation to Nano-technology and standardizing the development of Nano-tech industry.

Currently, a number of enterprises are said to be engaged in Nano-tech research, product development, marketing and etc., however, one cannot be sure how many are actual producers of Nano-tech products unless he or she undertakes an estimation. The distinctiveness of Nano-technology that deals with micro-world demands for an establishment of evaluation standard and the inspection to be strict and accurate. If one fails to satisfy this question, it might have a negative impact on the industrialization of Nano-technology. From this, many countries have established a standard related to Nano-technology and are offering technologies necessary in evaluating Nano-tech products by standardizing Nanotechnology so that its industrialization is headed to the right direction.

Today, the industrialization of Nano-technology is taking place in a direction where it is primarily applied in traditional industries.

Realizing the industrialization of Nano-technology by applying it in traditional industries has the advantages of obtaining a quick result and relatively easy generalization, while it takes low investment. Therefore, in order to provide favorable conditions for the industrialization of Nanotechnology, a number of countries are focusing on applying Nano-technology in traditional industries as to make people actually experience the advantages of Nano-technology.

The sectors where the bold achievements in applying Nano-technology to reorganize traditional industries are clearly demonstrated are precise chemical industry, textile industry, architecture, light industry, electric power industry and material industry. During the process of using Nanomaterials in textile industry, textile goods with superior functions, such as antibiosis control, infrared heat preservation, anion release, self-cleaning, water-proof and etc., have been developed and are already widely coming up on the market. Moreover, the paint made with Nanomaterials are becoming popular on the market as they have favorable features, such as reflection of infrared light, absorption of electromagnetic radiations, self-cleaning, antibiosis control and etc. In addition to this, Nano-tech introduced medicines, such as Nano-gene medicine, have come into the market and are warmly received by consumers. Nano-technology is applied in many other fields including energy and environmental protection and is yielding a number of achievements, and it has displayed a wide prospect of its industrialization.

As Nano-technology is becoming industrialized at a high speed, the marketing volume of Nano-tech products is increasing year after year. The global nanotechnology market is forecast to grow at a CAGR of around $17.5 \%$ during 20162022 period [1].

\section{The Development of Nano-technology and Its Industrialization in DPR of Korea}

DPRK put up Nano-technology as a core basic technology of modern development of science and technology along with information technology and bio-engineering, and established a firm foundation for its development by channeling great efforts into it.

In Juche 91 (2002), DPRK organized a science and technology examination commission for Nano-tech sector within the national system of scientific and technological examination, a branch examination commission for degree theses on Nano-tech science under the national conference committee of academic degrees and titles and Korea Nanotechnology Institution under the national committee of Korea Science and Technology Federation, thereby establishing a well-organized academic examination system for Nano-tech sector. And in Juche 102 (2013), DPRK established a coordinate leadership and an authentication and fund supply system for Nano-tech sector by organizing a national Nanotech agency under the national science and technology committee.

Also, DPRK organized a number of institutions specialized in Nano-tech research, such as National Nano-tech Agency, Nano-tech Research Institute of Kim Il Sung University, Nano-tech Research Institute of National Academy of Science, Nano-organic material laboratory in Field Biology Research Institute of National Academy of Science and Nano-medicine laboratory in Pharmacology Research Institute of Academy of Medical Science, and established a national system to promote Nano-tech exchange and widely spread Nano-technology. Services, distributions and exchanges of Nano-tech related information are taking place via LANs; national and international scientific seminars, scientific and technological public presentations, exhibitions and short-term courses in Nano-tech sector are organized regularly; and Nano-tech related information is widely introduced and published via science films, TVs, radios and various publications.

In higher educational institutions, including Kim Il Sung 
University, Kim Chaek Engineering University and University of Natural Science, they organized Nano-tech related courses and special classes, and are training a number of well-qualified scientists and technicians majored in Nanotechnology.

As a result of intensified research work in higher educational institutions, scientific research organizations and production units, a large number of achievements have been made in Nano-tech sector in the past years.

Nano-material Sector

They established a Nano-material production base and a process of producing various metal, nonmetal and metallic oxide Nano-materials by supercritical fluid method, and are doing a research work to apply them to various subjects.

The research work to fabricate Nano-metal and introduce them to fuel production is taking place and the technology of producing DNA chips has been perfected.

In various scientific research institutions, they are applying Nano-powder of various metal and nonmetal oxides, such as Nano-zinc oxide, Nano-titanium dioxide, Nano-silicon dioxide, Nano-aluminum oxide and etc., in various fields and sectors.

Also, they have made a composition device for carbon Nano-materials and are using it to compose Nano-materials, such as carbon Nano-pipe; and now working on producing an ionic line erosion device which can be used in the production of Nano-class structural frame. Furthermore, they have designed and manufactured a magnetron double target sputtering device, manufactured multilayered Nano-plastic sheets that have super magneto-resistance effect and are now studying its applications in various projects, such as sensor cells.

In addition, they have established the process of producing multilayered carbon Nano-pipes and graphens and started producing them; have manufactured Nano-silver high molecular compound power and is working on its application.

Nano-material Analysis and Measuring Sector

They have manufactured equipment for analyzing and measuring Nano-materials on their own and are using them for their research work.

They have manufactured a scanning microscope, an atompowered microscope and a laser growing-rice analyzer.

Nano-theory and Modeling Sector

The research work of Nano-theory and computer modeling sector is making progress on a high level.

Now they are doing a research work on theoretical and computer modeling method which can demonstrate the relation between Nano-scale structures and functions, Nanoscale conveyance and the operation theory of new Nanodemagnetizers and Nano-catalyzers.

Along with the research work on Nano-structure theory, they are conducting basic studies, such as dynamic study on molecules, on super-hydrophobic Nano-materials and Nanoporous materials.

Nano-tech Application Sector

The study on the application of Nano-tech in various fields is developing in depth.
In National Nano-tech Agency, they have established the process of producing Nano-titanium electrodes and Nanolubricant additives, and the study on solar cells and highcapacity batteries is being conducted.

In Kim Il Sung University, they have improved the quality of instruments using boron nitride super-hard materials, established an industrial production system, developed a quantum demagnetizer that uses macro-quantum refraction effect and test-made super-large capacity condenser. Along with this, they have manufactured Nano-gold and Nanosilver dispersion fluid and introduced them to public health sector.

In Kim Chaek Engineering University, they introduced various types of Nano-complex antibiosis materials to health and stockbreeding sectors. Also, they have manufactured compound solar cells $(\mathrm{CdS} / \mathrm{CdTe})$ and various types of functional Nano-compound materials and introduced them to various sectors of national economy.

In National Academy of Science, they have developed magnetic field sensors that use super magneto-resistance effect and applied them in measuring the magnetic field of the earth and detecting errors of metal products, and developed UV creams using Nano-materials, such as Nanotitanium dioxides.

In the Academy of Agricultural Science, they have developed Nano-disinfectants, Nano-organic growth promoters and Nano-photosynthesis reinforcing agents for agriculture and applied them in agricultural production.

In the Academy of Medical Science, they have completed manufacturing device for supercritical nanoparticles used for producing Nano-medicines and developed a method to fabricate Nano-materials used as a reflex in magnetic resonance image filming. They have also developed a method to examine hepatitis which uses Nano-gold material.

In Pyongyang Medical College of Kim Il Sung University, they have conducted a study on the antitumor effect of anticancer substances which used Nano-magnetic materials as a medicine carrier.

In the University of Natural Science, they have developed functional additives for 3-layer greenhouse plastic sheets.

In addition to this, many other achievements have been made, namely the completion of basic research on functional Nano-coating material and the construction of its production base.

\section{Conclusion}

There are many achievements made in the development of Nano-technology, however, there are a number of problems, all the same, that need to be solved in the future.

In National Science and Technology Committee and National Nano-tech Agency, they must establish a system where the work of Nano-tech sector is supervised in a unified way. Also, they must provide with major analyzing instruments needed for the analysis and certification of Nanomaterials, take appropriate measures for the cooperative use of scattered equipment used for studying and measuring 
Nano-materials and analyze and certify the Nano-materials of various units.

Secondly, we must strengthen the system of Nano-tech research and development.

We must organize Nano-tech research institutions in educational and scientific research institutions, factories and enterprises and take appropriate measures to strengthen the research capacity physical and technical foundations. Also, we must select right research assignments and organize the work so that the Nano-tech research institutions can make a great contribution to economic construction, strengthening national defense and the improvement of people's living. Furthermore, we must widely organize corporate and common research on the subjects of national importance through various forms and methods, strengthen the spread and exchange of Nano-technology, and raise the social interest on Nano-technology.

Third, we must bolster the work of training well-qualified scientists and technicians specialized in Nano-technology.

We must intentionally and prospectively proceed with the work of training scientists and technicians through education system. Along with this, we must let teachers, research scholars, postgraduates, students and engineers of production sites take active participation in accomplishing the Nano-tech research assignments, which will help them develop into well-qualified men of Nano-tech sector through practical process.

Fourth, we must take active measures to set investment plan and provide fund for Nano-tech sector.

We must set a national investment plan for the execution and the accomplishment of strategy of developing Nanotechnology and Nano-tech development plan by stages, and at the same time, take measures as to the educational and scientific research institutions and production enterprises provide fund on their own to their Nano-tech research institutions.

Also, we must take measures for the efficient use of provided fund. We must select the main research and development objects that can have international competitiveness according to the specific conditions of our country, concentrate investment on them and, therefore, raise its efficiency.

Fifth, we must establish a system to introduce the achievements of research work to production in time.

National Nano-tech Agency, Science and Technology Agencies of the ministries and national organs, Scientific and
Technical Examination Committee of Nano-tech sector and Branch Examination Committee for the degree theses on Nano-tech science must join efforts with each other and take measures to expand and introduce the achievements of Nanotech research of national importance in time.

If such problems are successfully solved, further progress will be made in terms of the development of Nano-tech and its industrialization, so that the DPR of Korea will have its own Nano industry in a nearby future.

\section{References}

[1] Global Nanotechnology Market Outlook 2022, Business Wire, March 24, 2016,

http://www.researchandmarkets.com/research/3bsn2g/global

[2] Economic Statistics \& Indicators, Nanotechnology Industries Association Logo.

[3] Quo vadis, worldwide nanoindustry?, Nanotechnologies in Russia, March 2016, Volume 11, Issue3, pp 117-127.

[4] S. Tinkle, S. E. McNeil, S. Muhlebach, R. Bawa, G. Borchard, Y. C. Barenholz, L. Tamarkin, and N. Desai, "Nanomedicines: addressing the scientific and regulatory gap," Ann. N. Y. Acad. Sci.1313, 35 (2014). CrossRef.

[5] K. James, "Nanotechnology market-nanotechnology markets in healthcare and medicine," Drug Developm. Deliv. (2014).

[6] A. L. Clunan and K. Rodine-Hardy, "Nanotechnology in globalized world, strategic assessment of an emerging technology," Project on Advanced Systems and Concepts for Countering WMD (PASCC) No. 2014-006.

[7] H. Flynn, "Nanotechnology update: corporations up their spending as revenues for nano-enabled products increase," in Proceedings of the Lux Executive Summit Europe Lux Research-2014, Amsterdam, Netherlands, Sept. 9-10, 2014.

[8] B. V. Romanovskii, Principles of Catalysis (Binom, Laboratoriya znanii, Moscow, 2014) [in Russian].

[9] Nanotechnology-A Global Strategic Business Report (Global Industry Analyst, Inc., 2014).

[10] "Nanoparticles in biotechnology, drug development and drug delivery," BIO113A (BCC Research, 2012).

[11] FDA: Guidance for industry considering whether and FDAregulated products involves the application of nanotechnology (2012). http://wwwfdagov/downloads/

RegulatoryInformation/Guidances/UCM401695pdf. 